\title{
Molecular screening for diseases frequent in Ashkenazi Jews: Lessons learned from more than 100,000 tests performed in a commercial laboratory
}

Charles M. Strom, MD, PhD, Beryl Crossley, MD, Joy B. Redman, MS, Franklin Quan, PhD, Arlene Buller, PhD, Matthew J. McGinniss, $P h D$, and Weimin Sun, $P h D$

\begin{abstract}
Purpose: To determine the frequency of carriers of Ashkenazi Jewish (AJ) genetic diseases in the US population and compare these numbers with previously published frequencies reported in smaller more isolated cohorts. Methods: A database containing more than 100,000 genotyping assays was queried. Assays for 10 separate AJ genetic diseases where comparisons were made with published data. Results: As expected, we observed lower carrier frequencies in a general, US population than those reported in literature. In 2427 patients tested for a panel of 8 AJ diseases, 20 (1:121) were carriers of two diseases and 331 (1:7) were carriers of a single disease. Fifty-three of 7184 (1:306) individuals tested for Gaucher disease had 2 Gaucher Disease mutations indicating a potentially affected phenotype. Conclusions: As the number of AJ diseases increases, progressively more individuals will be identified as carriers of at least one disease. Genet Med 2004:6(3):145-152.
\end{abstract}

Key Words: Ashkenazi Jews, genetic diseases, population screening

The Jewish people arose in the Middle East during the Bronze Age and have existed as a continuous community until present times. ${ }^{1}$ Traditionally, Jews have been divided into 3 major groups according to their regions of residence; Ashkenazi Jews (AJ), Oriental Jews, and Sephardic Jews. ${ }^{1}$ The United States has a population of approximately 5.7 million Jews and approximately $90 \%$ are classified as AJ. At least 18 genetic diseases are found predominantly in the AJ population, and another 10 are found in both the AJ population and other Jewish and non-Jewish populations. ${ }^{1}$

TSD has become the model system for genetic disease screening in the AJ population. Approximately 1:30 AJ individuals are carriers for TSD. ${ }^{2}$ The carrier rate in non-Jews is $<$ 1:300. Before carrier screening, TSD occurred with a frequency of 1:1200 in infants of AJ couples. Population-based screening programs for TSD in AJ individuals began in 1970 utilizing enzyme assays for the deficient enzyme hexosaminidase A (HexA) and resulted in a dramatic decrease in the incidence of $\mathrm{TSD}$ in the $\mathrm{AJ}$ population. $\mathrm{A}>90 \%$ reduction in the incidence of TSD in AJ couples has been achieved worldwide. ${ }^{2}$

The American College of Medical Genetics (ACMG) has issued guidelines recommending population-based carrier screening in the AJ population for two additional diseases to

Quest Diagnostics Nichols Institute, San Juan Capistrano, California.

Charles M. Strom, Quest Diagnostics Nichols Institute, 33608 Ortega Highway, San Juan Capistrano, CA 92690.

Received: January 2, 2004.

Accepted: February 4, 2004.

DOI: 10.1097/01.GIM.0000127267.57526.D1
TSD, Canavan Disease (CD) in $1998,{ }^{3}$ and Cystic Fibrosis (CF) in 2001. ${ }^{4}$ ACMG recommends screening for CD be offered to couples when both parents are $\mathrm{AJ}$ and that couples should be informed about the availability and limitations of $\mathrm{CD}$ carrier testing when one partner is $\mathrm{AJ}{ }^{3}$ The $\mathrm{ACMG}$ recommends screening for all $\mathrm{AJ}$ individuals for CF. ${ }^{4}$ Published literature describes the carrier frequencies for $\mathrm{CD}$ and $\mathrm{CF}$ in the AJ population as approximately $1: 41^{5}$ and $1: 28,{ }^{6}$ respectively.

With the advent of molecular testing, studies were performed to determine the most effective method of AJ carrier screening for TSD. Triggs-Raine et al. ${ }^{7}$ demonstrated that using enzyme analysis alone would result in a false-negative rate of 1:152 and a false-positive rate of 1:6. A second study demonstrated a false-negative rate of 1:25 and a false-positive rate of 1:4 using biochemical testing alone. ${ }^{8}$ These studies concluded that maximum sensitivity and specificity are obtained when both DNA and enzyme testing are used. Two other extensive studies compared the efficacy of using DNA alone or enzymatic testing alone for population-based TSD carrier detection in the AJ population. Both studies concluded that if a single test is used, DNA testing is the method of choice., ${ }^{9,10}$

Carrier detection by DNA testing is potentially available for at least 8 additional AJ diseases and many physicians request population-based carrier screening for some or all of these disorders. For the past 2 years, our laboratory has been offering carrier testing for TSD, CD, CF, Gaucher Disease (GD), Bloom Syndrome (BS), Familial Dysautonomia (FD), Fanconi Anemia Complement Group C (FAC), and Niemann-Pick Disease (NPD). Recently, testing for Mucolipidosis IV (ML IV) has 
been added. We have performed more than 100,000 genotyping assays for AJ genetic diseases on samples referred to our laboratory throughout the US. It is not possible to assure that there is no ascertainment bias in these samples, however, consistency with published literature suggests that if such biases exist, their effect is minimal.

With rare exceptions, published carrier frequencies for AJ diseases are based on the analysis of one of 3 groups: Dor Yeshorim (the Committee for Prevention of Jewish Diseases), New York City Jewry, and Israeli populations. Dor Yeshorim is a world-wide community of observant Jewry whose policy is to test all individuals anonymously during their high school years and to arrange marriages that do not pair 2 carriers of the same genetic disease. This highly successful program does not disclose the testing results to patients or their families. The Israeli and New York populations are geographically isolated. These 3 groups most often studied are likely to be more homogeneous than the US AJ population as a whole and therefore may not accurately represent carrier frequencies of the general American AJ population. An additional problem of populationbased screening for AJ genetic diseases is the potential misidentification of an individual as AJ.7 It is more likely that an individual in Dor Yeshorim, Israel, and metropolitan New York is accurately identified as an $\mathrm{AJ}$ than an individual from outside those communities.

Quest Diagnostics is a national laboratory accepting specimens from throughout the United States. We analyzed the data from more than 100,000 individual tests performed on more than 15,000 patients and made comparisons to previously published series. All our observed carrier frequencies are lower than those reported in the literature, which is not unexpected given the more diffuse nature of our test population. Because these data are derived from much larger populations and are from a general US population who identify themselves as AJ, these figures can be used for genetic counseling of AJ couples in the US who are not tested in the Dor Yeshorim program or who reside outside the New York metropolitan area. In addition, these data could be used to craft a coherent policy for population-based carrier testing in $\mathrm{AJ}$ individuals in the general US population.

\section{METHODS}

\section{Patient population}

Our laboratory maintains a proprietary database containing the results of all molecular genetic testing. We cannot determine which tests have been ordered for diagnostic testing versus population-based carrier detection but it is assumed that the overwhelming majority of tests are ordered for carrier detection. We also have no assurance that the samples have been submitted from $\mathrm{AJ}$ individuals, but we assume that the overwhelming majority of tests are sent from AJ individuals. Currently, we offer each of the $9 \mathrm{AJ}$ tests listed in the introduction as separate tests. We also offer an $\mathrm{AJ}$ panel that includes the 8 tests listed in the introduction. ML IV is not currently on the AJ panel as this test was only recently added to our test menu.
Our database was queried to determine the data for this report. All patients were included unless otherwise noted. We initially separated the data into individuals whose physicians ordered individual tests and those whose physicians ordered an AJ panel of 8 tests. The distribution of mutations and the carrier frequencies did not differ between groups so the data were pooled for this report (Chi square test, data not shown).

\section{Molecular testing}

CF genotype analysis was initially performed using Roche CF Gold Line Probe Assay Strips (Roche Molecular Systems), and then the assay was changed to the Celera CF OLA Genotyper V. 3.0 (Abbott) as described previously. ${ }^{11}$

A detailed description of test methodology is beyond the scope of this publication. In summary, assays for 4 mutations in TSD, 4 mutations in GD, 3 mutations in CD, and 4 mutations in NPD were performed using laboratory developed assays and SnapShot kits provided by Applied Biosystems Incorporated (ABI) under a licensing agreement from Orchid Technologies. Following standard PCR, extension primers of varying lengths are annealed to the amplicons. Each extension primer is specific for a single site and ends one base upstream from the mutation site. Primer extension is performed using four dideoxynucleotide triphosphates each having a different colored fluor. Samples were analyzed on an ABI 3100 automated DNA analyzer. Each size is specific for a single mutation pair and the color or colors at that size indicate the genotype. Automated allele calling was accomplished using ABI software with proprietary macros. After review the results are uploaded into our laboratory information system.

Single mutation assays for BS, FD, and FAC were performed using the Promega ReadIT platform. After routine PCR, the amplicons are aliquotted into two microtiter wells and allele specific interrogation primer is added to each well. The interrogation primers are designed so that a mutation will cause a mismatch in the penultimate nucleotide. After annealing the interrogation primers to the amplicons, excess pyrophosphate is added. In the presence of a perfect match, a triphosphate is generated and when a mismatch is present a monophosphate is generated. The formation of triphosphates are assayed by a luciferase reaction, and the results are read in an automated fluorometer, automated allele calling is accomplished using the Promega ReadIT Calculator, and after review, the results are uploaded into our laboratory information system.

Two mutations in the ML IV gene were analyzed using realtime Taqman PCR performed on an ABI 7900 with automated allele calling performed by proprietary software. In the assay, PCR is performed in the presence of allele specific probes that contain a fluor and a quencher. If the allele-specific probe binds to the amplicon, the 5 ' exonuclease activity of Taq polymerase cleaves the fluor from the quencher allowing fluorescence to accumulate. With the exception of $\mathrm{CF}$, all tests were in-house proprietary laboratory developed tests. 


\section{RESULTS}

\section{Ashkenazi Jewish screening panel}

In all, 2,427 patients were tested for the AJ panel of 8 disorders: CF, TSD, CD, GD, BS, FAC, FD, and NPD. Twenty patients were found to be carriers of 2 different diseases, and 331 were found to be carriers of a single disorder. Therefore nearly $15 \%$ of all individuals tested had at least one abnormal result that should result in recommendations for follow-up genetic counseling and an option for testing their spouse.

\section{Cystic fibrosis}

Table 1 is the distribution of CF mutant alleles discovered in the series of 2,780 patients whose physicians ordered the panel of 8 diseases. The sequence variant I148T was excluded from this analysis since its association with CF disease is unclear. We detected 88 patients with CF mutations, a carrier frequency of $1: 28$. This carrier frequency and the distribution of mutations is similar to that reported in the literature in the AJ population. ${ }^{6}$ As expected, 2 mutations, delta F508 and W1282X accounted for most of the CF chromosomes with 35 (40\%) and $32(36 \%)$ individuals, respectively.

\section{Tay Sachs disease}

TSD is a devastating autosomal recessive (AR) lysosomal storage disease caused by a defective enzyme, Hexosaminidase A (HexA). Although there is a rare adult onset form, almost all patients with TSD present in the first year of life and die before the age of 6 after prolonged neurological deterioration. We tested 18,002 patients for the 3 most common AJ mutations in TSD: TATCins1278, G269S, and IVS12+1G $>$ C. In addition,

Table 1

CF genotyping results from $2780 \mathrm{AJ}$ panels

\begin{tabular}{lcc}
\hline Mutation & $\begin{array}{c}\text { No. } \\
(\% \text { CF chromosomes })\end{array}$ & Frequency \\
\hline$\Delta$ F508 & $35(40 \%)$ & $1: 79$ \\
W1282X & $32(36 \%)$ & $1: 77$ \\
$3849+10 \mathrm{~kb} \mathrm{C}>\mathrm{T}$ & $4(4.5 \%)$ & $1: 695$ \\
N1303K & $4(4.5 \%)$ & $1: 695$ \\
R117H & $3(3.4 \%)$ & $1: 926$ \\
G542X & $2(2.2 \%)$ & $1: 1,390$ \\
A455E & $1(1 \%)$ & $1: 2780$ \\
$3120+1 G>A$ & $1(1 \%)$ & $1: 2780$ \\
2184 del A & $1(1 \%)$ & $1: 2780$ \\
R334W & $1(1 \%)$ & $1: 2780$ \\
G551D & $1(1 \%)$ & $1: 2780$ \\
$\Delta$ I507 & $1(1 \%)$ & $1: 2780$ \\
$1717-1$ G $>$ A & $1(1 \%)$ & $1: 2780$ \\
G85E & $1(1 \%)$ & $1: 2780$ \\
Total & 87 & $1: 32$ \\
\hline
\end{tabular}

the "pseudodeficiency allele," R247W, was analyzed. This missense mutation is known to cause false-positive results in the biochemical Hex A assay. Table 2 contains a summary of 18,002 TSD carrier tests performed. In all, 496 carriers were identified indicating a carrier frequency 1:36. The pseudodeficiency allele was discovered in 38 individuals, an incidence of 1:473. Because the HexA enzyme analysis will identify approximately 1:30 AJ as TSD carriers, approximately 1:16 of these individuals will actually be noncarriers who possess the pseudodeficiency allele. This emphasizes the importance of confirming all suspected TSD carriers first identified by HexA enzyme screening by then using DNA testing. If one or both parents of a fetus are carriers of the pseudodeficiency allele and DNA testing is not performed, a subsequent prenatal diagnostic test could yield spurious positive enzyme results, resulting in the termination of an unaffected fetus. In addition, such a couple is at unnecessary and avoidable risk of a pregnancy loss due to prenatal diagnostic procedure.

Table 3 examines the distribution of the 4 common AJ TSD alleles compared to those found in the literature. $.^{7,8,10,12,13} \mathrm{Al}-$ though the overall carrier frequency of 1:36 is slightly lower than the 1:30 reported by Kaback et al., ${ }^{2}$ there are no unexpected findings in these data.

\section{Gaucher disease}

There are 3 types of GD. Type I, also known as the nonneuropathic form, is the most common in the AJ population. Onset can be at any age, but is always progressive. Due to a deficiency of the lysosomal enzyme glucocerebrosidase, macrophages become swelled with undigested material leading to the formation of cells known as Gaucher cells. Eventually, bone marrow cavities and the spleen become filled with Gaucher cells. Hypersplenism results in pancytopenia and hepatosplenomegaly. Bone weakness can cause fractures and spinal cord compressions and chronic pain. If an early or presymptomatic diagnosis is made, enzyme replacement therapy has been shown to be effective in preventing morbidity and mortality. However, once fractures have occurred, therapy cannot reverse the weakened bony structures so it is imperative to treat patients before they become symptomatic. Because many patients will not have their initial symptoms until adulthood,

Table 2

Allele frequencies in 18,002 Tay Sachs Carrier DNA tests ${ }^{a}$

\begin{tabular}{lrcc}
\hline Genotype & No. & $\begin{array}{c}\text { Carrier } \\
\text { frequency }\end{array}$ & $\begin{array}{c}\% \text { TSD } \\
\text { alleles }\end{array}$ \\
\hline wt/wt & 17468 & NA & NA \\
wt/TATCins1278 & 385 & $1: 47$ & $78 \%$ \\
wt/IVS 12(G->C) & 78 & $1: 230$ & $16 \%$ \\
wt/G269S & 33 & $1: 545$ & $7 \%$ \\
R247W (Pseudodeficiency) & 38 & $1: 473$ & NA \\
All carriers & 496 & $1: 36$ & NA \\
\hline
\end{tabular}

${ }^{a}$ The results of 2 affected patients were removed from these data. 
Table 3

Literature comparison of frequency of Tay Sachs alleles in AJ population. Frequencies indicate percentage of all TSD alleles discovered in that particular study

\begin{tabular}{|c|c|c|c|c|c|c|c|}
\hline Genotype & $\begin{array}{l}\text { Current study } \\
\quad N=496\end{array}$ & $\begin{array}{l}\text { Bach et al }^{9} \\
N=151\end{array}$ & $\begin{array}{l}\text { Kaback }^{2} \\
N=239\end{array}$ & $\begin{array}{c}\text { Triggs-Raine et } \mathrm{al}^{7} \\
N=62\end{array}$ & $\begin{array}{c}\text { DeMarchi et al }{ }^{10} \\
N=52\end{array}$ & $\begin{array}{l}\text { Paw et al }{ }^{12} \\
N=156\end{array}$ & $\begin{array}{c}\text { Grebner and Tomczak }{ }^{13} \\
\qquad N=128\end{array}$ \\
\hline TATCins 1278 & $78 \%$ & $90 \%$ & $80 \%$ & $72 \%$ & $92 \%$ & $73 \%$ & $76 \%$ \\
\hline IVS $12+1 \mathrm{G}->\mathrm{C}$ & $16 \%$ & $8.1 \%$ & $9 \%$ & $13 \%$ & $1.8 \%$ & $14 \%$ & $20 \%$ \\
\hline G269S & $7 \%$ & $2 \%$ & $3 \%$ & ND & $0 \%$ & $4 \%$ & $7.0 \%$ \\
\hline Overall carrier frequency & $1: 36$ & NA & $1: 30$ & NA & $1: 25$ & NA & NA \\
\hline Population & $\begin{array}{l}\text { USA Carrier } \\
\text { Screen }\end{array}$ & $\begin{array}{l}\text { Dor Yeshorim } \\
\text { Combined } \\
\text { obligate carrier } \\
\text { and affected }\end{array}$ & Carrier Screen & Obligate Carrier & $\begin{array}{l}\text { Dor Yeshorim } \\
\quad \text { Carrier Screen }\end{array}$ & $\begin{array}{l}\text { Carrier by } \\
\text { enzyme assay }\end{array}$ & $\begin{array}{l}\text { Combined obligate } \\
\text { carrier and affected }\end{array}$ \\
\hline
\end{tabular}

establishing the diagnosis of GD in an asymptomatic pregnant woman can allow her to begin treatment during the asymptomatic portion of her disease. Therapy can be safely administered during pregnancy. Estimates of the frequency of Type I GD are 1:450-1:1500 in $\mathrm{AJ}$ and at least 100 times less frequent in non-AJ populations. ${ }^{10,14,15}$ Hardy-Weinberg calculations predict a carrier frequency in $\mathrm{AJ}$ of 1:10-1:19. Given the high incidence of GD in the AJ population, we would expect to identify not only GD carriers, but also presymptomatic GD patients in a pregnancy screening program.

Table 4 shows the data of 7184 patients tested for GD. We found a carrier frequency of 1:19 consistent with the literature prediction. We found 53 patients with 2 GD mutations leading to an incidence of 1:306. Given a carrier frequency of 1:19, we would expect only 1:1444 affected individuals. Our data are most likely skewed due to the fact that some of the samples were submitted from patients known or suspected to have GD.

Table 5 shows a literature comparison of Gaucher allele frequencies with our current data. Of note is that in the two studies using a carrier-screened population, N370S is present at a higher frequency than in patients ascertained secondary to a diagnosis of Type I GD. There are 2 potential explanations for

\section{Table 4}

Genotype data for Gaucher disease testing of 17,184 patients

\begin{tabular}{lrc}
\hline Genotype affected & $\begin{array}{c}\text { Combined } \\
\text { no. }\end{array}$ & $\begin{array}{c}\text { Combined } \\
\text { incidence }\end{array}$ \\
\hline N370S/1035 insG & 2 & $1: 8593$ \\
N370S/L444P & 4 & $1: 4296$ \\
N370S/N370S & 45 & $1: 381$ \\
Total affected & 51 & $1: 306$ \\
Carriers & & \\
wt/1035 ins G & 30 & $1: 572$ \\
wt/IVS 2(+1) G $>$ A & 7 & $1: 2455$ \\
wt/L444P & 17 & $1: 1010$ \\
wt/N370S & 834 & $1: 21$ \\
Total carriers & 888 & $1: 19$ \\
wt/wt & 16245 & \\
\hline
\end{tabular}

these data. N370S may demonstrate incomplete penetrance or patients identified in carrier screening programs who are homozygous for N370S may be presymptomatic because many GD patients do not present until later in life. N370S is known to be a milder mutation than the other GD mutations and may therefore be associated with later onset of symptoms. That would make these presymptomatic patients excellent candidates for enzyme replacement therapy. These data raise the issue that screening males together with their female partners may help identify those at risk for late-onset disease, in addition to its usefulness as a carrier screen. The same number of males are predicted to have 2 GD alleles and could be candidates for enzyme replacement therapy. Further data regarding the clinical course of asymptomatic patients homozygous for N370S is necessary before determining if this genotype has incomplete penetrance or exhibits variability in the age of onset and whether these individuals would benefit from enzyme replacement therapy.

\section{Canavan disease}

Similar to TSD, CD is a neurodegenerative lysosomal storage disease. Three mutations in the aspartoacyclase gene, E285A, A305E, and Y231X, are responsible for more than 98\% of cases of CD. ${ }^{16}$ We decided to include A305E in our screening panel despite its low reported frequency because it added minimal cost to the test and we wished to establish its frequency in the US population. Table 6 summarizes the genotyping data from 19,790 consecutive CD genotype analyses and compares these data with 3 literature reports. ${ }^{16-18}$ Our observed carrier frequency of 1:65 is slightly lower than that of the other studies. The most striking observation, however, is the paucity of patients with A305E. Only 3 patients were observed in almost 20,000 analyses. Matalon ${ }^{17}$ found no patients with this genotype. The low incidence of this mutation calls into question the utility of including this mutation in routine AJ carrier screening panels. Detection of such rare events is technically difficult and increases the chances of false positive results. Analysis of A305E is probably best reserved for affected individuals and obligate CD carriers. 
Table 5

Literature comparison of Gaucher allele frequencies

\begin{tabular}{|c|c|c|c|c|}
\hline Allele & $\begin{array}{l}\text { This study } \\
N=888\end{array}$ & $\begin{array}{c}\text { DeMarchi et al }{ }^{10} \\
\quad N=110\end{array}$ & $\begin{array}{c}\text { Grabowski }{ }^{14} \\
N=1160 \text { alleles }\end{array}$ & $\begin{array}{c}\text { Koprivica et a } \mathrm{a}^{15} \\
N=108 \text { alleles }\end{array}$ \\
\hline 1035 ins $\mathrm{G}$ & $3.3 \%$ & $6.4 \%$ & $11 \%$ & $0.92 \%$ \\
\hline IVS $2(+1) G>A$ & $0.78 \%$ & $0.9 \%$ & $1.7 \%$ & $4.6 \%$ \\
\hline L444P & $1.9 \%$ & $3.6 \%$ & $4.1 \%$ & $2.8 \%$ \\
\hline N370S & $94 \%$ & $89 \%$ & $72 \%$ & $71 \%$ \\
\hline Carrier frequency & $1: 19$ & $1: 12$ & NA & NA \\
\hline Population & USA Carrier screen & Dor Yeshorim Carrier screen & USA Patients with Type 1 & USA Patients with Type 1 \\
\hline
\end{tabular}

Table 6

Literature comparison of Canavan disease allele frequencies

\begin{tabular}{|c|c|c|c|c|}
\hline & A305E no. (\%) & E285A no. (\%) & Y231X no. (\%) & Carrier frequency \\
\hline Current study $N=19,790$ & $3(1 \%)$ & $264(87 \%)$ & $37(12 \%)$ & $1: 65$ \\
\hline Elpeleg ${ }^{18}$ (Israel) $N=879$ & $\mathrm{ND}^{a}$ & 15 & $\mathrm{ND}^{a}$ & $1: 59$ \\
\hline Kronn \& Oddoux et al. ${ }^{5}$ New York $N=449$ & $\mathrm{ND}^{a}$ & $10(91 \%)$ & $1(9 \%)$ & $1: 41$ \\
\hline Matalon ${ }^{17} N=2700$ & 0 & $52(87 \%)$ & $8(13 \%)$ & $1: 45$ \\
\hline
\end{tabular}

${ }^{a} \mathrm{ND}$, Not determined.

\section{Bloom syndrome}

Bloom Syndrome is a disorder characterized by short stature, immunodeficiency, chromosome instability, and predisposition to cancer. A single complex rearrangement of the $B L M$ gene known as BLM ${ }^{\text {Ash }}$ is responsible for more than $99 \%$ of BS cases in AJ populations. Table 7 contains data from our series of 12,025 patients compared to literature reports. We observed a carrier frequency of 1:164, lower than 4 published studies that reported frequencies of between 1:100 and $1: 110,{ }^{19-22}$ but higher than one study which demonstrated a frequency of 1:231. ${ }^{23}$ These differences probably result from the fact that each study used a different population for its analyses.

\section{Fanconi anemia type C}

Fanconi anemia type $\mathrm{C}$ causes limb abnormalities, bone marrow failure, and propensity to leukemia and other malig-

Table 7

Bloom Syndrome literature comparison ${ }^{a}$

\begin{tabular}{lcc}
\hline Study & No. screened & $\begin{array}{c}\text { Carriers found } \\
\text { (frequency) }\end{array}$ \\
\hline Current study (US) & 12,025 & $73(1: 164)$ \\
Peleg et al. ${ }^{19}$ (Israel) & 4,001 & $36(1: 111)$ \\
Roa et al. ${ }^{20}$ (US) & 1,016 & $10(1: 102)$ \\
Li et al. ${ }^{21}$ (New York) & 1491 & $14(1: 107)$ \\
Shahrabani ${ }^{22}$ (Israel) & 1,613 & $16(1: 100)$ \\
Oddoux et al. ${ }^{23}$ (New York) & 1,155 & $5(1: 231)$ \\
\hline
\end{tabular}

${ }^{a}$ All populations were Ashkenazi Jews for carrier screening. nancies. A single mutation in the FAC gene, IVS4 $+4 \mathrm{~A}>\mathrm{T}$, accounts for more than $99 \%$ of FAC in Ashkenazi Jewish patients. ${ }^{24}$ Table 8 displays our data for 12,282 genotypes and also shows literature data. We observed a carrier frequency of 1:108. Previously reported frequencies vary from 1:89 to $1: 157.19,24,25$

\section{Familial dysautonomia}

Also known as Riley-Day syndrome, FD is a protean disorder characterized by decreased sensitivity to pain and temperature, cardiovascular instability, recurrent pneumonias, vomiting crises, and gastrointestinal dysfunction. ${ }^{26} \mathrm{~A}$ single intronic mutation in the IKBKAP gene $(2507+6 \mathrm{~T}>\mathrm{C})$ accounts for more than $99 \%$ of AJ FD chromosomes. ${ }^{26,27}$ Table 9 is a compilation of the 9,703 genotypes performed by our laboratory and also shows two published reports. We observed a frequency of 1:42, only slightly lower than the frequency found in the Dor Yeshorim and New York populations of 1:30 and $1: 32$, respectively.

Table 8

Fanconi anemia type C-IVS $4+4 \mathrm{~A}>\mathrm{T}$ mutation

\begin{tabular}{lcc}
\hline & $\begin{array}{c}\text { Carriers } \\
\text { detected }\end{array}$ & $\begin{array}{c}\text { Carrier } \\
\text { frequency }\end{array}$ \\
\hline Current study (US) $N=12,282$ & 113 & $1: 108$ \\
Auerbach $^{24}$ (New York) $N=3,104$ & 35 & $1: 89$ \\
Whitney $^{25}$ (US) $N=314$ & 2 & $1: 157$ \\
Peleg et al. ${ }^{19}$ (Israel) $N=4,029$ & 44 & $1: 92$ \\
\hline
\end{tabular}


Table 9

Familial dysautonomia 2507+6 T $>$ C mutation

\begin{tabular}{lcc}
\hline & No. of carriers & Carrier frequency \\
\hline Current study $N=9,703$ & 232 & $1: 42$ \\
Anderson $^{26}$ (Dor Yeshorim) $N=819$ & 27 & $1: 30$ \\
Dong $^{27}$ (New York) $N=2,518$ & 79 & $1: 32$ \\
\hline
\end{tabular}

\section{Niemann-Pick disease}

There are 4 major AJ mutations in the NPC-1 gene described to cause NPD: delR608, fsP330, L302P, and R496L. Table 10 displays our genotyping results for 10,421 patients and data reported in a review of Schuchman and Miranda. ${ }^{28}$ We observed a lower percentage of the L302P mutation ( $8 \%$ vs. 39\%) in our series and a lower over all carrier frequency (1:125 vs. $1: 90)$ than reported in the literature. ${ }^{28}$

\section{Mucolipisosis IV}

The assay for the two AJ mutations in ML IV, del6.4kb and IVS3 $-2 \mathrm{~A}>\mathrm{G}$, was recently added to our test menu. Thus far, we have analyzed 2,006 patients for these mutations and have found 4 patients with del $6.4 \mathrm{~kb}$ and 7 patients with IVS $3-2 \mathrm{~A}>\mathrm{G}$, leading to a carrier frequency of $1: 182$. This is lower than the 1:127 reported by Edelman et al. ${ }^{29}$ in a cohort of 2,029 individuals from the greater New York area. Our observed prevalence of IVS 3-2A $>$ G represents approximately $64 \%$ of mutations is similar to the $68 \%$ observed by Edelman. ${ }^{29}$

\section{Nonclassical congenital adrenal hyperplasia}

New and colleagues described a mutation in the CYP 21 gene that causes a nonclassical congenital adrenal hyperplasia (NCAH) phenotype when homozygous or when compound heterozygous with a classical CAH mutation. The NCAH phenotype consists of subfertility, hirsutism, and excess urinary excretion of steroids. ${ }^{30}$ We de-identified and analyzed 1143 samples sent for AJ panel testing and found 132 (1:9) heterozygous individuals and 8 (1:142) homozygous individuals. Chi square analysis revealed that this is in a Hardy-Weinberg distribution. Because the samples were de-identified it was not possible to obtain clinical information regarding the 8 homozygous individuals. Because samples were de-identified before testing, no IRB approval was required.

Table 10

Literature comparison of Niemann-Pick disease allele frequencies

\begin{tabular}{lcc}
\hline Mutation & $\begin{array}{c}\text { Current study } \\
N=10,421\end{array}$ & Schuchman $^{28}$ \\
\hline delR608 & $3(4 \%)$ & rare \\
fsP330 & $33(40 \%)$ & $25 \%$ \\
L302P & $7(8 \%)$ & $39 \%$ \\
R496L & $42(50 \%)$ & $43 \%$ \\
Total mutations & $83(1: 125)$ & $1: 90$ \\
\hline
\end{tabular}

\section{DISCUSSION}

Our data represents the largest published series of carrier screening results for a general US AJ population. Table 11 lists our observed carrier frequencies in descending order of occurrence. Carrier frequencies are $>1: 100$ for only 6 diseases: $\mathrm{NCAH}, \mathrm{GD}, \mathrm{CF}, \mathrm{TSD}, \mathrm{FD}$, and CD. Using TSD and a carrier frequency of 1:30 as a model system, it seems reasonable to include these 6 diseases on any AJ screening panel in the US AJ population. However, NCAH and GD can often be mild diseases with adult onset. Screening for these disorders may be more appropriate for general screening to identify affected individuals and allow treatment. Steroid replacement will alleviate masculinizing effects of NCAH including hirsutism and can restore full fertility for affected women. Enzyme replacement therapy for asymptomatic affected men and women could prevent development of subsequent debilitating and lifethreatening morbidities from GD. However, GD may also present with neonatal or juvenile onset and have severe neurologic sequela.

We observed carrier frequencies of $<1: 100$ for 4 disorders: NP, BS, FAC, and ML IV. Although our carrier frequencies are slightly lower than literature reports, even these reports show carrier frequencies of $<1: 100$ with the exception an estimate of 1:90 by Schuchman for NP. ${ }^{28}$ With carrier frequencies of 1:100 or greater, fewer than 1:10,000 at-risk couples will be identified for a particular disease. Most laboratories may not identify a single at-risk couple in a year of testing for each of these disorders. Carrier frequency is only one of many criteria to consider in population-based screening, including cost-effectiveness of screening, severity of the disease, and potential other benefits such as identifying affected individuals with adult onset disorders (GD) and emotional benefit to the couples.

As the fruits of the completed Human Genome Project are reaped, more genes will be identified and mapped to various population groups and an increasing number of genes and mutations will be identified as causing AJ genetic diseases. Should each disease be added to population-based AJ screen-

\section{Table 11}

Listing of this laboratory's observed carrier frequencies in $\mathrm{AJ}$ in a large unselected US population

\begin{tabular}{lc}
\hline Disorder & Carrier frequency \\
\hline Atypical congenital adrenal hyperplasia & $1: 9(0.11)$ \\
Gaucher disease & $1: 19(0.052)$ \\
Cystic fibrosis & $1: 28(0.031)$ \\
Tay Sachs disease & $1: 36(0.027)$ \\
Familial dysautonomia & $1: 42(0.023)$ \\
Canavan disease & $1: 65(0.015)$ \\
Fanconi anemia type C & $1: 108(0.092)$ \\
Niemann-Pick disease & $1: 125(0.008)$ \\
Bloom syndrome & $1: 164(0.006)$ \\
Mucolipidosis IV & $1: 182(0.005)$ \\
\hline
\end{tabular}


ing or should some criteria be applied in terms of carrier frequency and/or disease severity? Carrier frequencies of 1:14 and 1:21 have been reported for mutations in the GJB2 gene that cause nonsyndromic deafness in the homozygous state and in association with at least one other gene, GJB6. ${ }^{31-33}$ Screening $\mathrm{AJ}$ women for 3 founder mutations in breast cancer genes with a prevalence of 1:40 has been suggested. ${ }^{34}$ Mutations causing Factor XI deficiency ${ }^{35}$ (AJ carrier frequency 1:21), and Usher Syndrome ${ }^{36}$ (AJ carrier frequency 1:72) have recently been described. Carrier frequencies as high as 1:5 have been observed in some Sephardic Jewish populations for familial Mediterranean Fever. ${ }^{37}$ Plans to perform population-based carrier screening for congenital hearing loss, clotting abnormalities, or other nonfatal diseases are being debated. We must be careful to differentiate population-based genetic screening performed primarily for the purposes of identifying at-risk couples to enable prenatal and preimplantation genetic diagnosis from those whose primary purpose is to perform presymptomatic or confirmatory diagnosis (i.e., Gaucher disease, Familial Mediterranean fever, Factor XI deficiency, ACAH, and breast cancer screening). It is our opinion that lumping tests primarily useful for carrier detection with those useful for diagnosis into a single AJ panel is a disservice to patients and the physicians who care for them.

As progressively more disorders are added to the screening list, an increasing number of individuals will be discovered to carry at least one recessive allele. In our current study, approximately 1 in every 7 individuals tested for 8 AJ diseases was discovered to be a carrier of at least one disorder. Each of these individuals becomes a candidate for genetic counseling services, with the recommendation of genetic screening of their reproductive partner and has the potential to cause great emotional distress. ${ }^{38,39}$ As multiplex mutation platforms are perfected, it will be possible to screen a single specimen for many mutations at a reasonable cost. However, beginning a screening program simply because one has the technical ability to do so could lead to ever increasing burdens on the health care delivery system. These burdens will be both financial and in service demands for necessary genetic counseling. The stigmatization felt by some patients when informed they carry a genetic disease is real and may endure despite adequate genetic counseling. ${ }^{38}$

Most would agree that there should be some threshold prevalence of carriers in a population group before the introduction of population-based carrier screening for a severely debilitating or fatal disease. From the current recommendation by the ACMG for AJ screening for CD, CF, and TSD, it can be inferred that frequencies in the 1:30-1:45 range are appropriate for screening. If that is the only criteria for screening, $\mathrm{FD}$ should be added to list. Although GD is often a mild or late onset disease in AJ, some patients have severe disease, and population-based screening would have an added benefit of identifying presymptomatic, affected patients and would allow monitoring and early therapeutic intervention. Screening for congenital nonsyndromic hearing loss would be more controversial given the progress of cochlear implant therapy and the ability of hearing impaired individuals to live productive lives. This type of screening is probably more appropriate in the newborn screening arena as an adjunct to current audiology methods.

Using the TSD model, there was consensus regarding the appropriateness of screening AJ individuals for TSD because of the carrier frequency of 1:30 in this population. Conversely, there was a consensus that the non-Jewish TSD carrier frequency of 1:300 is below the threshold for population-based carrier screening in the general US population. ${ }^{2}$ Largely due to this decision and the success of screening programs in the AJ population, more cases of TSD are currently diagnosed in nonJews than in AJ couples. ${ }^{2}$ The very success of the TSD screening program in the AJ populations leads to some difficult questions. Should we expand TSD carrier detection to non-Jews in order to further reduce the incidence of the disease? If 1:300 is beneath the threshold for population-based screening, what about the 1:182 for ML IV, the 1:164 for BS, and the 1:125 for NP?

Fragile $\mathrm{X}$ syndrome (FraX) is the most common form of inherited mental retardation. It is an X-linked genetic disease causing moderate to severe mental retardation in males and attention-deficit disorder and learning disability in females. ${ }^{40}$ FraX is seen in similar frequencies in all races and ethnic groups. Two recent study of Israeli women of reproductive age discovered carrier frequencies of 1:70 in 9459 women $^{41}$ and $1: 113$ in 14,334 women, ${ }^{42}$ respectively. Because this is an Xlinked disease all carrier females are at risk for conceiving affected children. Even using the lesser value, screening for FraX would yield a more than 8 -fold higher rate of detecting at risk couples than a Tay-Sachs disease screening program in AJ populations. A FraX screening program in the Caucasian population would discover more at-risk couples than a CF screening program (1:70-1:259 vs. 1:784 couples). A further benefit of benefit of population-based screening for FraX is that once a single carrier is discovered, testing of extended family members often leads to identification of other at-risk women. Carrier screening for FraX in both the general US population and in the AJ population seems warranted at this time.

Based on our data, population-based carrier screening for NP disease would result in $<1$ in 15,000 at-risk couples identified, more than 16-fold less than the 1:900 AJ couples who will be at risk for TSD. At-risk couples for ML IV and BS will be even scarcer. It is important for professional organizations such as ACMG to determine the cost-benefit ratio of such programs and provide guidance for the appropriateness of testing. This publication supplies realistic figures for actual carrier detection in a general US AJ population. Data such as this will be vital to creating a coherent policy for population-based carrier screening in the AJ community.

\section{References}

1. Ostrer H. A genetic profile of contemporary Jewish populations. Nat Rev Genet 2001;2:891-898.

2. Kaback M, Lim-Steele J, Dabholkar D, Brown D, Levy N, Zeiger K. Tay-Sachs Disease - Carrier screening, prenatal diagnosis and the molecular era. JAMA 1993;270: 2307-2315. 


\section{Strom et al.}

3. American College of Medical Genetics. Position statement on carrier testing for Canavan's Disease Testing. Available at: http://www.acmg.net/resources/policies/ pol_003.asp. Accessed February 2, 2004.

4. American College of Medical Genetics. Laboratory Standards and Guidelines for Population-based Cystic Fibrosis Carrier Screening. Available at: http://www.acmg.net/resources/policies/pol_005.asp. Accessed February 2, 2004.

5. Kronn D, Oddoux C, Phillips J, Ostrer H. Prevalence of Canavan disease heterozygotes in the New York metropolitan Ashkenazi Jewish population. Am J Hum Genet 1995;57:1250-1252.

6. Kerem B, Chiba-Falek O, Kerem E. Cystic fibrosis in Jews: Frequency and mutation distribution. Genet Test 1997;1:35-39.

7. Triggs-Raine BL, Feigenbaum ASJ, Natowicz M, Skomorowski M-A, Schuster SM, Clarke JTR et al Screening for carriers of Tay-Sachs disease among Ashkenazi Jews; A comparison of DNA-based and enzyme based tests. N Engl J Med 1990;323:6-12.

8. Fernandes MJG, Kaplan F, Clow CL, Hechtman P, Scriver CR. Specificity and sensitivity of hexosaminidase assays and DNA analysis for the detection of Tay-Sachs disease gene carriers among Ashkenazic Jews. Genet Epidemiol 1992;9:169-175.

9. Bach G, Tomczak J, Risch N, Ekstein J. Tay-Sachs screening in the Jewish Ashkenazi population: DNA testing is the preferred procedure. Am J Med Genet 2001;99:7077.

10. DeMarchi JM, Caskey T, Richards C. Population-specific screening by mutation analysis for diseases frequent in Ashkenazi Jews. Hum Mutat 1996;8:116-125.

11. Strom C, Huang D, Buller A, Redman J, Crossley B, Anderson B et al. Cystic Fibrosis Screening Using the College Panel: Platform Comparison and Lessons Learned from the First 20,000 Samples. Genet Med 2002;4:289-296.

12. Paw B, Tieu PT, Kaback MM, Lim J, Neufeld EF. Frequency of three Hex A mutant alleles among Jewish and non-Jewish carriers identified in a Tay-Sachs screening program. Am J Hum Genet 1990;47:698-705.

13. Grebner EE, Tomczak J. Distribution of Three $\alpha$-chain $\beta$-hexosaminidase a mutations among Tay-Sachs carriers. Am J Hum Genet 1991;48:604-607.

14. Grabowski GA. Gaucher disease: Gene frequencies and genotype/phenotype correlations. Genet Test 1997;1:5-12.

15. Koprivica V, Stone DL, Park JK, Callahan M, Frisch A, Cohen IJ et al. Analysis and classification of 304 mutant alleles in patients with type 1 and type 3 Gaucher disease. Am J Hum Genet 2000;66:1777-1786.

16. Kaul R, Gao GP, Aloya M, Balamurugan K, Petrosky A, Michals K et al. Canavandisease: mutations among Jewish and non-Jewish patients. Am J Hum Genet 1994; 55:34-41.

17. Matalon R. Canavan disease: diagnosis and molecular analysis. Genet Test 1997;1: 21-25.

18. Elpeleg ON, Anikster Y, Barash V, Branski D, Shaag A. The frequency of the C854 mutation in the aspartoacylase gene in Ashkenazi Jews in Israel. Am J Hum Genet 1994;55:287-288.

19. Peleg L, Pesso R, Goldman B, Dotan K, Omer M, Friedman E et al. Bloom Syndrome and Fanconi Anemia: Rate and ethnic origin of mutation carriers in Israel. Isr Med Soc J 2002;4:95-97.

20. Roa BB, Savino CV, Richards CS. Ashkenazi Jewish population frequency of the Bloom syndrome gene 2281 6ins7 mutation. Genet Test 1999;3:219-221.

21. Li L, Eng C, Desnick RJ, German J, Ellis NA. Carrier frequency of the Bloom syndrome blmAsh mutation in the Ashkenazi Jewish population. Mol Genet Metab 1998;64:286-290.

22. Shahrabani-Gargir L, Shomrat R, Yaron Y, Orr-Urtreger A, Groden J, Legum C. High frequency of a common Bloom syndrome Ashkenazi mutation among Jews of Polish origin. Genet Test 1998;2:293-296.

23. Oddoux C, Clayton, Carlos M, Nelson HR, Ostrer H. Prevalence of Bloom syndrome heterozygotes among Ashkenazi Jews. Am J Hum Gen 1999;64:1241-1243.
24. Auerbach AD. Fanconi anemia: genetic testing in Ashkenazi Jews. Genet Test 1997; $1: 27-33$.

25. Whitney M, Jakobs P, Kaback M, Moses RE, Grompe M. The Ashkenazi Jewish fanconi anemia mutation: incidence among patients and carrier frequency in the at-risk population. Hum Mutat 1994;3:339-341

26. Anderson SL, Coli R, Daly IW, Kichula EA, Rork MJ, Volpi SA et al. Familial dysautonomia is caused by mutations of the IKAP Gene. Am J Hum Genet 2001;68:753758.

27. Dong J, Edelmann L, Bajwa AM, Kornreich R, Desnick RJ. Familial dysautonomia: detection of the IKBKAP IVS20 $(+6 \mathrm{~T}>\mathrm{C})$ and R696P mutations and frequencies among Ashkenazi Jews. Am J Med Genet 2002;110:253-257.

28. Schuchman EH, Miranda SRP. Neimann-Pick disease: Mutation update, genotype/ phenotype correlations, and prospects for genetic testing. Genet Test 1997;1:13-19.

29. Edelman L, Dong J, Desnick RJ, Kornreich R. Carrier screening for mucolipidosi type IV in the American Ashkenazi Jewish population. Am J Hum Genet 2002;70: 1023-1027.

30. Wilson RC, Wei J-Q, Cheng KC, Mercado AB, New MI. Rapid deoxyribonucleic acid analysis by allele-specific polymerase chain reaction for detection of mutations in the steroid 21-hydroxylase gene. J Clin Endocrinol Metab 1995;80:1635-1640.

31. Morel RJ, Kim HJ, Hood LJ, Goforth L, Friderici K, Fisher R et al. Mutations in the connexin 26 gene (GJB2) among Ashkenazi Jews with nonsyndromic recessive deafness. N Engl J Med 1998;339:1500-1505.

32. Lerer I, Sagi M, Malamud E, Levi H, Raas-Rothschild A, Abeliovich D. Contribution of Connexin 26 mutations to nonsyndromic deafness in Ashkenazi Patients and the variable phenotypic effect of the mutation 167delT. Am J Med Genet 2000;95:53-56

33. Del Castillo I, Moreno-Pelayo MA, Del Castillo FJ, Brownstein Z, Marlin S, Adina Q et al. Prevalence and evolutionary origins of the del (GJB6-D13S1830) mutation in the DFNB1 locus in hearing impaired subjects: a multicenter study. Am J Hum Genet 2003;73:1452-1458.

34. Robson M, Dabney MK, Rosenthal G, Ludwig S, Seltzer MH, Gilewski T et al Prevalence of Recurring BRCA mutations among Ashkenazi Jewish women with breast cancer. Genet Test 1997;1:47-51.

35. Goldstein DB, Reich DE, Bradman N, Usher S, Seligsohn U, Peretz H. Age estimate of two common mutations causing Factor XI deficiency: Recent genetic drift is not necessary for elevated disease incidence among Ashkenazi Jews. Am J Hum Genet 1999;64:1071-1075.

36. Ben-Yosef T, Ness SL, Madeo MS, Bar-Lev MS, Wolfman JH, Ahmed ZM et al. A mutation of PCDH15 among Ashkenazi Jews with type 1 Usher Syndrome. N Engl J Med 2003;348:1664-1670.

37. Oberkanins C, Weinhausel A, Kriegshauser G, Moritz A, Kury F, Hass OA. Genetic testing for Familial Mediterranean Fever in Austria by means of reverse-hybridization test strips. Clin Chem 2003;49:1948-1950.

38. Markel H. The stigma of disease: Implications of genetic screening. Am J Med 1992 93:209-215.

39. Sorenson JR. Some social and psychologic issues in genetic screening: Public and professional adaptation to biomedical innovation. Birth Defects Orig Artic Ser 1974; 10:165-84.

40. Hagerman R, Miri K, Conister A. Fragile X checklist. Am J Hum Genet 1991;38:579589

41. Pesso R, Berkenstadt M, Cuckle H, Gak E, Peleg L, Frydman M et al. Screening for Fragile X Syndrome in women of reproductive age. Prenat Diagn 2000;20:611-614

42. Toledano-Alhadef H, Basel-Vanagaite L, Magal N, Davidov B, Ehrlich S, Drasinover $\mathrm{V}$ et al. Fragile-X carrier screening and the prevalence of premutation and full mutation carriers in Israel. Am J Hum Genet 2001;69:351-360. 